\title{
Author Correction: Scalable high-precision tuning of photonic resonators by resonant cavity- enhanced photoelectrochemical etching
}

\author{
Eduardo Gil-Santos ${ }^{1}$, Christopher Baker ${ }^{1}$, Aristide Lemaître ${ }^{2}$, Sara Ducci ${ }^{1}$, Carmen Gomez ${ }^{2}$, Giuseppe Leo ${ }^{1}$ \& \\ Ivan Favero ${ }^{1}$
}

Correction to: Nature Communications 8:14267; https://doi.org/10.1038/ncomms14267; published online 24 Jan 2017

The original version of this Article omitted the fourth author, Sara Ducci from Matériaux et Phénomènes Quantiques, Université Paris Diderot, CNRS UMR 7162, Sorbonne Paris-Cité, 10 rue Alice Domon et Léonie Duquet, Paris 75013, France. This mistake has been corrected in both the HTML and PDF versions of the Article.

Published online: 28 August 2018

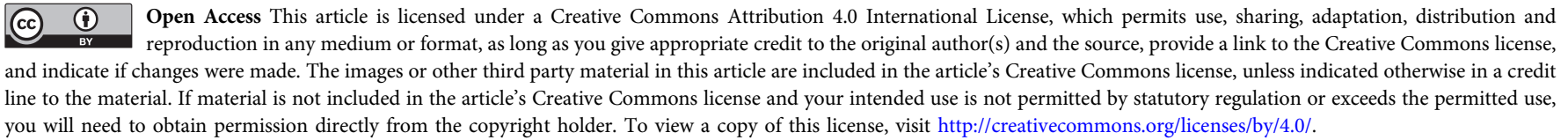
you will need to obtain permission directly from the copyright holder. To view a copy of this license, visit http://creativecommons.org/licenses/by/4.0/.

(c) The Author(s) 2018

\footnotetext{
${ }^{1}$ Matériaux et Phénomènes Quantiques, Université Paris Diderot, CNRS UMR 7162, Sorbonne Paris-Cité, 10 rue Alice Domon et Léonie Duquet, 75013 Paris, France. ${ }^{2}$ Laboratoire de Photonique et de Nanostructures, Route de Nozay, CNRS, 91460 Marcoussis, France. Correspondence and requests for materials should be addressed to I.F. (email: ivan.favero@univ-paris-diderot.fr)
} 